\title{
Object-based Dune Analysis: Automated dune mapping and pattern characterization for Ganges Chasma and Gale crater, Mars
}

\author{
David A. Vaz ${ }^{\text {a,b,* }}$, Pedro T.K. Sarmento ${ }^{a}$, Maria T. Barata ${ }^{\text {a }}$, Lori K. Fenton ${ }^{\text {c }}$, Timothy I. Michaels ${ }^{\text {c }}$ \\ a Centre for Earth and Space Research of the University of Coimbra, Observatório Geofisico e Astronómico da Universidade de Coimbra, Almas de Freire, 3040 -004 Coimbra, Portugal \\ b CERENA - Centre for Natural Resources and the Environment, Instituto Superior Técnico, Av. Rovisco Pais, 1049-001 Lisboa, Portugal \\ c SETI Institute, Carl Sagan Center, 189 Bernardo Ave Suite 100, Mountain View, CA, USA
}

\section{A R T I C L E I N F O}

\section{Article history:}

Received 3 June 2015

Received in revised form 27 August 2015

Accepted 30 August 2015

Available online 3 September 2015

Keywords:

Dune mapping

Object-based image analysis

Pattern recognition

Mars surface

\begin{abstract}
A B S T R A C T
A method that enables the automated mapping and characterization of dune fields on Mars is described. Using CTX image mosaics, the introduced Object-based Dune Analysis (OBDA) technique produces an objective and reproducible mapping of dune morphologies over extensive areas. The data set thus obtained integrates a large variety of data, allowing a simple cross-analysis of dune patterns, spectral and morphometric information, and mesoscale wind models.

Two dune fields, located in Gale crater and Ganges Chasma, were used to test and validate the methodology. The segmentation of dune-related morphologies is highly efficient, reaching overall accuracies of $95 \%$. In addition, we show that the automated segmentation of slipface traces is also possible with expected accuracies of 85-90\%. A qualitative and quantitative comparison of the final outputs with photointerpretations is performed, and the precision of the directional characterization of the dune patterns is evaluated. We demonstrate a good agreement between the OBDA outputs and the photointerpreted dune morphologies, with local trend deviations below $45^{\circ}$ for $80-95 \%$ of the mapped areas. Because the developed algorithm is tuned for the recognition of linear features from the imagery, the slipfaces of small barchans can be preferentially overlooked owing to their small extent at the spatial resolution of the CTX mosaics. Dune types composed of longer linear morphologies are much better represented, including correct mapping of secondary structures. Having proved the effectiveness and accuracy of the mapping procedure, we discuss its future applications for the improvement of dune catalogs on Mars.
\end{abstract}

(c) 2015 Elsevier B.V. All rights reserved.

\section{Introduction}

Dune fields are good indicators of past and present aeolian transport regimes (Kocurek and Ewing, 2005; Beveridge et al., 2006). On Earth, remote sensing data gives a wider perspective and provides context for local field observations of aeolian processes (Elbelrhiti et al., 2008), showing the relationship between regional sediment transport trends and atmospheric circulation patterns (du Pont et al., 2014; Fenton et al., 2014a). The relationship between bedforms and atmospheric circulation patterns is particularly important for other planets, where direct measurements of wind velocities and trends are not typically available. For instance on Mars, mapping yardangs, wind streaks, and dune fields is critical for inferring large-scale atmospheric dynamics (Ward et al., 1985; Fenton et al., 2005; Hayward et al., 2009; Silvestro et al., 2010; Gardin et al., 2012; Sefton-Nash et al., 2014).

The more complete source of information about Martian dune fields is the Mars Global Digital Dune Database (MGD ${ }^{3}$ ) (Hayward et al., 2007, 2014). It is a digital compilation of the location and characteristics of the

\footnotetext{
* Corresponding author at: CITEUC - Observatório Geofísico e Astronómico da Universidade de Coimbra, Almas de Freire, 3040-004 Coimbra, Portugal.

E-mail address: davidvaz@uc.pt (D.A. Vaz).
}

main dune fields on Mars. Parameters such as intracrater dune field centroids with respect to crater centroids, dune slipface orientations, and inferred wind directions were mapped (Fig. 1C), providing a unique global view of the interplay between the atmosphere and sedimentary dynamics on the planet.

The dune fields in the $\mathrm{MGD}^{3}$ were mapped and characterized manually through the photointerpretation of $100 \mathrm{~m} /$ pixel THEMIS (THermal EMission Imaging System) imagery. The perimeters of the dune fields were digitized and slipface orientations were mapped in selected areas. These features are used to estimate the trends of the prevailing winds at the surface. Because the data coverage of the Context Camera (CTX) imagery (Malin et al., 2007) that we used in our study is nearly global at a spatial resolution of $<10 \mathrm{~m} /$ pixel, this data set will certainly provide a more detailed view of the dune fields, complementing the existing information for each dune field. Because it would be very difficult and costly to do such mapping manually for all the dune fields on the planet, automation is required in order to maximize the extraction of valuable geomorphological information from the imagery.

Dune slipfaces, crestlines, and other morphological features are traditionally manually digitized and later analyzed using different sets of statistical and spatial techniques (Greeley and Thompson, 2003; Ewing et al., 2006; Silvestro et al., 2010; Fenton et al., 2014a, 2014b). 

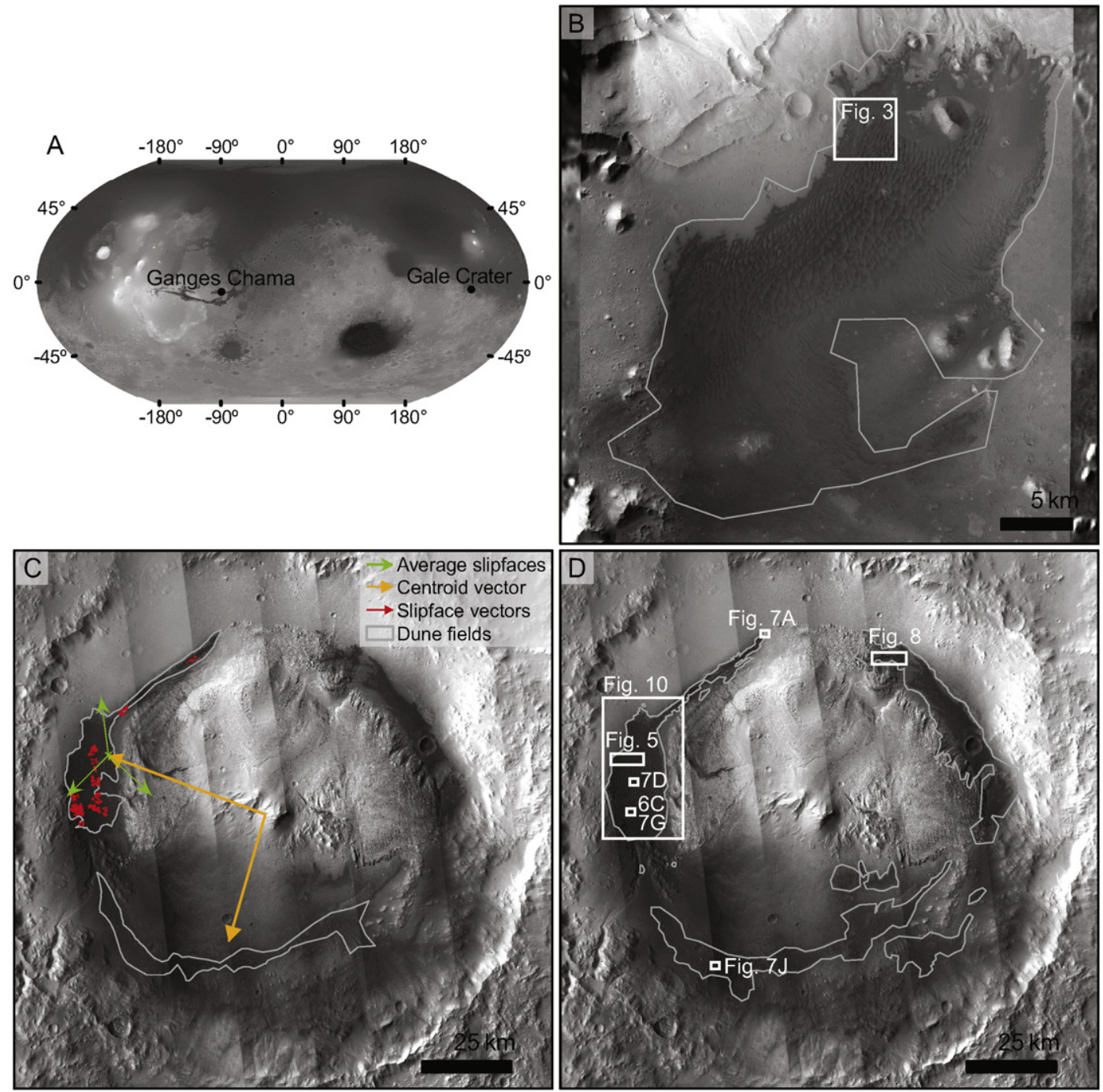

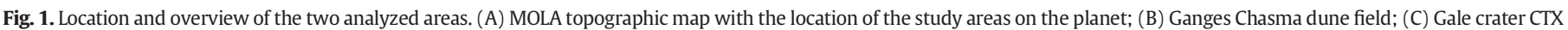

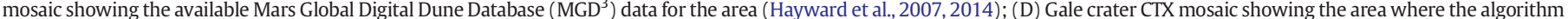
was applied.

However, the mapping and discretization of aeolian features from remote sensing data is a task that involves some degree of user bias (Hugenholtz et al., 2012), which may constitute an obstacle to the integration and standardization of observations.

Previous examples of automatic characterization of aeolian features from remote sensing data include the monitoring of dune migration (Vermeesch and Drake, 2008; Necsoiu et al., 2009), detection and delimitation of dunes on Mars Orbiter Camera (MOC) data (Bandeira et al., 2011), and mapping and characterization of ripple patterns on Mars using HiRISE (High Resolution Imaging Science Experiment) data (Silvestro et al., 2013; Vaz and Silvestro, 2014). With the purpose of mapping automatically the crests of linear dunes from Landsat imagery, Telfer et al. (2015) used a Sobel operator for performing edge detection. Using SAR data, the trends of dune fields on Titan were surveyed using a linear segment detection algorithm (von Gioi et al., 2012; Lucas et al., 2014). This last example shows how the application of image processing techniques can be a powerful tool for the characterization of dune patterns at a global scale. More recently, the same linear segment detection technique was tested on Mars for mapping aeolian landforms using a CTX image (Fernandez-Cascales et al., 2015).

In this paper, we will introduce a new way to analyze the dune patterns on Mars using the dune fields within Ganges Chasma and Gale crater (Fig. 1) to test and validate the technique. We call this methodology
Object-based Dune Analysis (OBDA), and it enables the automated mapping and characterization of aeolian dune morphologies over large areas, allowing a future update of the existing Martian dune catalogs.

\section{Data and study areas}

\subsection{Data}

The data sets used to identify and map the dune morphologies are CTX mosaics obtained using ISIS (Integrated Software for Imagers and Spectrometers) software. To reduce illumination variations, the images used to produce the mosaics were geometrically corrected and normalized. The spatial resolution of the Gale crater and Ganges Chasma mosaics used in this work was 6 and $7 \mathrm{~m} /$ pixel, respectively. For the characterization of the mapped morphologies, other auxiliary data sets were used: MOLA (Mars Orbiter Laser Altimeter) and HRSC (High Resolution Stereo Color imager) digital terrain models (DTMs), as well as day and night infrared THEMIS mosaics (Edwards et al., 2011).

The validation data sets correspond to the dune morphologies (essentially lines representing dune crests and slipfaces) mapped through manual photointerpretation of the CTX mosaics using ArcGIS. For the Ganges Chasma area we use the same data set mapped and discussed 


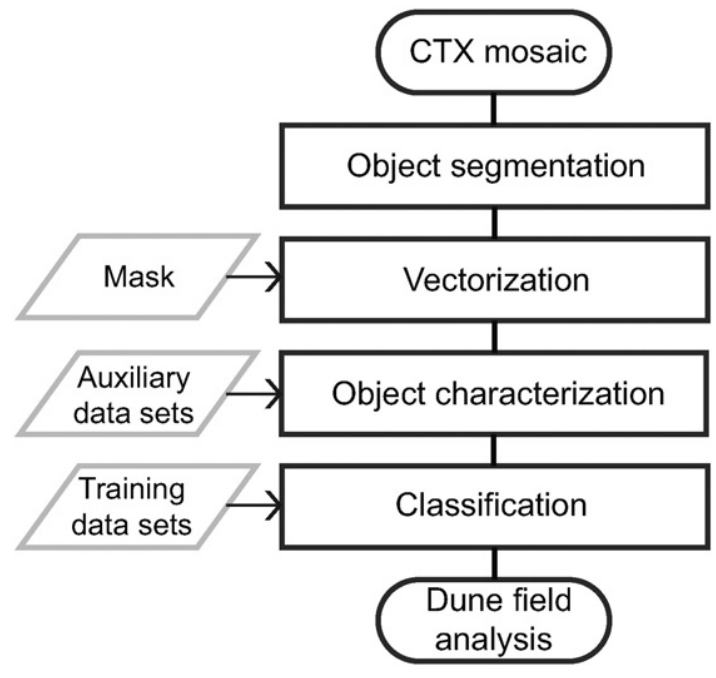

Fig. 2. Flowchart with the main steps of the OBDA mapping technique. by Fenton et al. (2014b). Sediment transport vectors inferred from the dune morphologies were collected for the Gale crater area by adapting and complementing the data presented by Hobbs et al. (2010).

Modeled mesoscale wind fields for Gale crater were used for comparison with the trends of the automatically mapped surface features. The mesoscale atmospheric model used in this work was MRAMS (Mars Regional Atmospheric Modeling System), which was first described in Rafkin et al. (2001) and with further updates in Michaels and Rafkin (2008). This is a nonhydrostatic, fully compressible, regional (i.e., not global) model that uses multiple telescoping computational grids to estimate/predict the atmospheric conditions on Mars at relatively high resolution. A set of four MRAMS runs targeting Gale crater at representative seasons (corresponding to solar longitudes $L_{s} \sim 30$, 120,210 , and $300^{\circ}$ ) was performed. The surface aerodynamic roughness length $\left(z_{0}\right)$ was set to a constant value $(0.03 \mathrm{~m})$ over the entire MRAMS domain, as a result of the lack of $z_{0}$ spatial distribution data for Mars. The terrain and surface characteristics for these MRAMS simulations were based on $1 / 128^{\circ}$ gridded MOLA topography (Smith et al., 2001) and $1 / 20^{\circ}$ gridded TES (Thermal Emission Spectrometer) albedo and nighttime thermal inertia (Putzig and Mellon, 2007). The nested grid
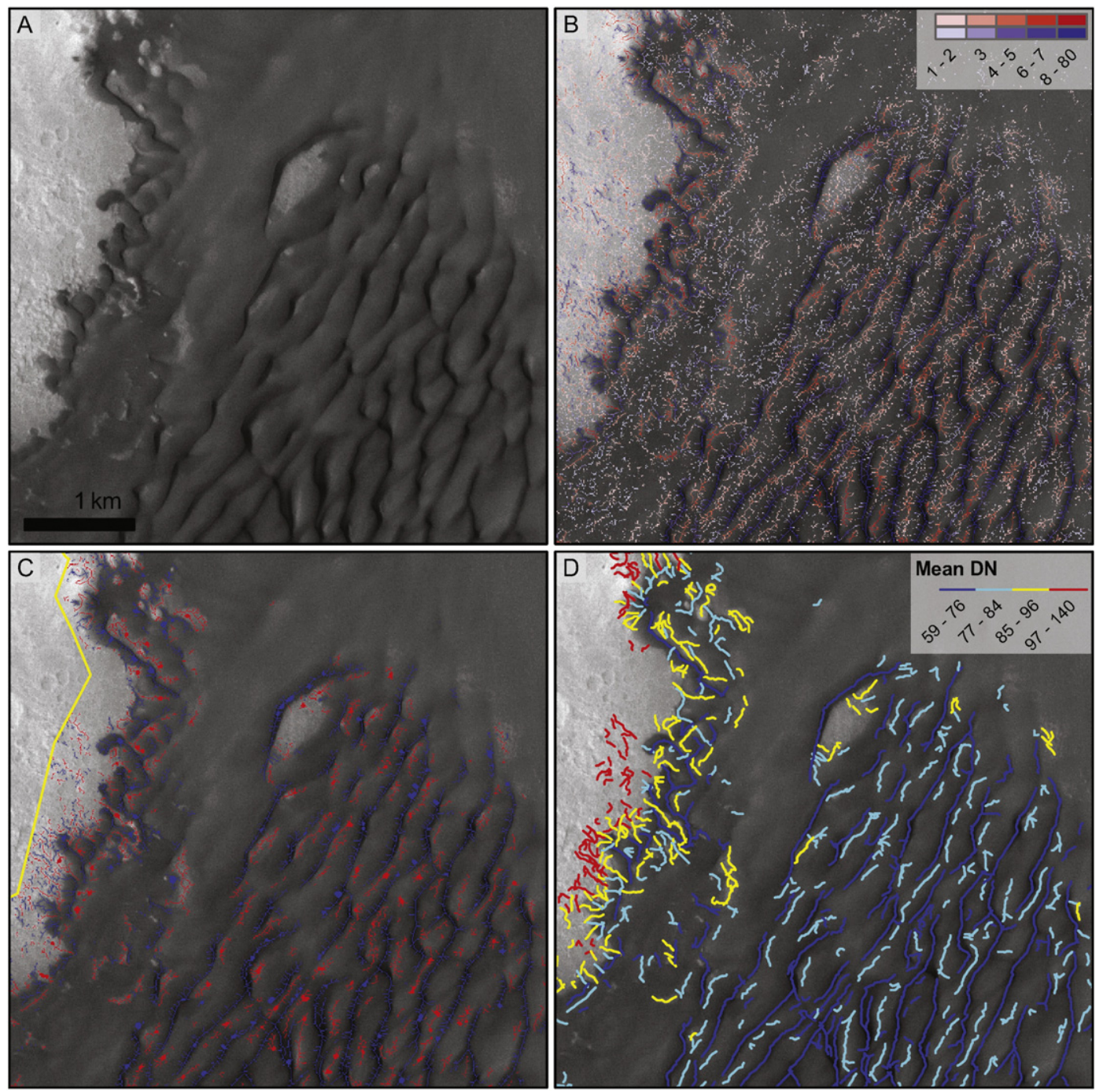

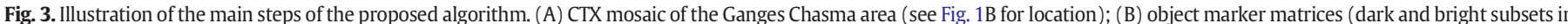

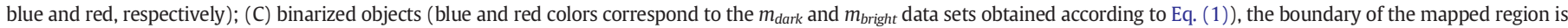

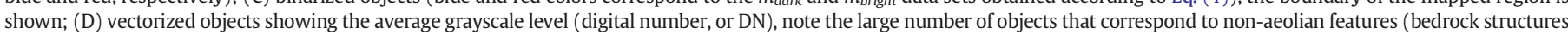
for instance) and how slipfaces are well represented. 

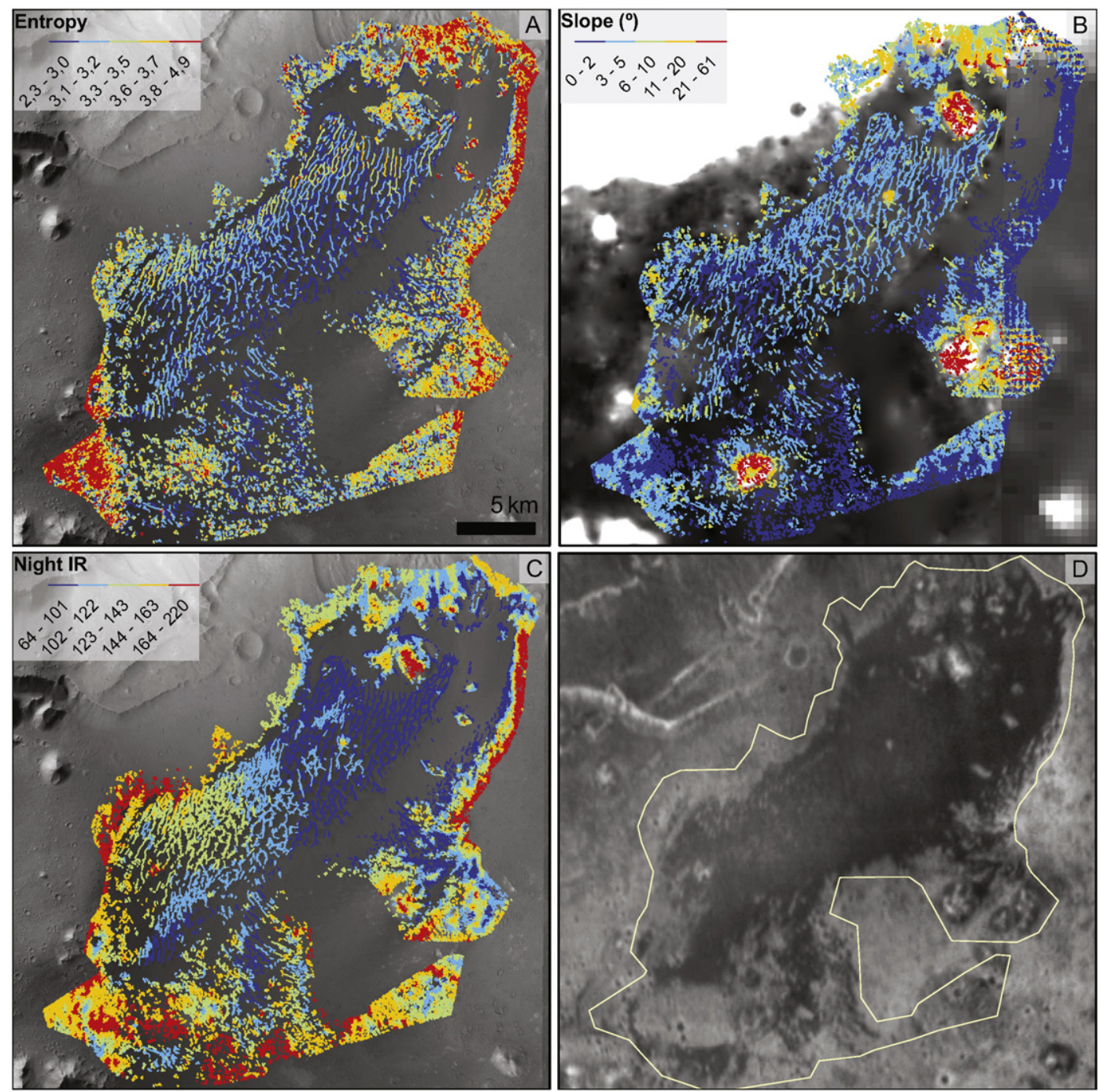

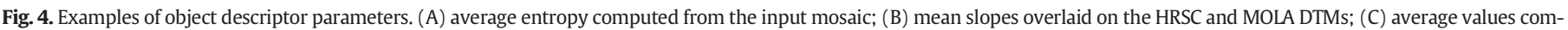
puted for each object using the mosaic shown in (D); (D) THEMIS nighttime mosaic, note the coarser resolution and the clear thermophysical signature of the aeolian deposits.

used for the analysis reported here has a grid spacing of $\sim 2 \mathrm{~km}$, providing a satisfactory number of samples over the targeted dune field. MRAMS output from the first Mars-day of each run was not analyzed, as model spin-up is still occurring then. The ratio between the modeled instantaneous aerodynamic surface stress and the aerodynamic stress threshold for saltation initiation (Greeley and Iversen, 1985) is used as a proxy for the amount of mobilized sediment.

\subsection{Aeolian settings}

The two selected areas (Fig. 1A) were chosen because they present a large diversity of dune types, trends, and morphologies. The same Ganges Chasma dune field $\left(7.7^{\circ} \mathrm{S}, 45.25^{\circ} \mathrm{W}\right)$ that was used to test the application of the inverse maximum gross bedform-normal transport formalism (Fenton et al., 2014b) is used in this study to test and validate the mapping procedure (Fig. 1B). This dune field is located near the northern wall of the $\sim 5$-km-deep Chasma depression, and the dunes span an area of $\sim 500 \mathrm{~km}^{2}$. The several overlapping sets of differently oriented dunes that exist in this area seem to be coeval, indicating a complex wind regime with main wind flows trending ESE, NE, SW, and NW. The location of the dune field corresponds approximately to the convergence point of these flows. Present day activity was also reported, indicating that at least some of the dunes are actively migrating (Fenton et al., 2014b).

Gale crater is located in the Aeolis quadrangle near the boundary between the northern lowlands of Elysium Planitia and the southern highlands of Terra Cimmeria $\left(5.4^{\circ} \mathrm{S}, 137.7^{\circ} \mathrm{E}\right)$ and presents a complex array of dune fields surrounding Mt. Sharp, a 5.5-km-high mountain on the central crater floor (Fig. 1C, D). Hobbs et al. (2010) mapped the dune fields and presented the general transport trends, showing that they are largely influenced by the central mountain topography. Barchan, barchanoid, dome, reverse, and transverse dunes are present, and their spatial distribution is consistent with predominant regional winds blowing from N-NW, which are accelerated and deflected by the crater topography.

Using HiRISE data, evidence of present-day aeolian activity was identified (Silvestro et al., 2013; Vaz and Silvestro, 2014), proving that the dunes in northern Gale crater are active and migrating. A limitation of this type of high-resolution analysis is that because of the incomplete data coverage, it fails to provide a continuous perspective of the sediment transport processes. Thus, a fast and efficient way to map dune morphology and identify sediment transport paths, such as the one 
introduced in this work, would also be useful to evaluate current dune activity and migration on Mars.

\section{Methods}

The proposed methodology is based on an object-based image analysis (OBIA) approach, also referred to as GEOBIA (geographic object-based image analysis; Hay and Castilla, 2008). It consists of the application of image segmentation techniques in order to extract image objects (sets of pixels) whose descriptors (parameters that characterize those objects) can be used to implement higherlevel classification and analysis (Blaschke, 2010). In comparison with classic per-pixel spectral classification techniques, OBIA can produce more accurate results (Myint et al., 2011; Whiteside et al., 2011).

The same generic technique was successfully applied on Mars to map and analyze tectonic structures from DTMs (Vaz, 2011; Vaz et al., 2012, 2014) and aeolian ripples from HiRISE imagery (Silvestro et al., 2011, 2013; Vaz and Silvestro, 2014). The common point in these examples is that image recognition techniques can be used to identify linear objects with a single well-constrained geomorphological meaning. These objects can then be used to characterize the geological processes responsible for their formation/evolution.

Fig. 2 shows the flowchart of the proposed algorithm. Linear bright and dark ridges are first segmented from the CTX mosaic; the segmented objects are then vectorized and characterized by collecting geometric, textural, morphometric, and spectral descriptors. Finally, the mapped linear objects are used for the implementation of a supervised classification scheme in order to remove non-aeolian objects (mainly bedrock features) and to segment the population of objects that correspond to slipfaces.

\subsection{Object segmentation and characterization}

Dune morphologies are commonly mapped and discretized using line segments. Dune slipfaces and crests are the basic morphologies typically mapped by photointerpretation. In the CTX mosaics these morphologies correspond to linear bright or dark ridges, depending on the relation between the illumination setting (sub solar azimuth) and the trends and types of dunes. Longitudinal, transverse, reverse, or star dunes tend to form longer linear structures, making them more easily recognizable in contrast with small barchans, whose slipfaces are sometimes difficult to identify (Fig. 3).

To obtain marker matrices for the bright and dark linear ridges, we employ a set of mathematical morphological operators (for a comprehensive review of mathematical morphology image processing refer to Soille, 2002). A mean filter with a $3 \times 3$ kernel is first applied to smooth the input mosaic $(g)$ and remove high-frequency noise. Morphological orientation fields are then computed using linear structuring elements with a size of 19 pixels and angular intervals of $10^{\circ}$. The difference between the field strengths computed by opening $\left(g \operatorname{dir}_{\lambda}^{\chi}(f)\right)$ and closing $\left(\operatorname{gdir}_{\lambda}^{\phi}(f)\right)$ (Soille, 2002) provides the primary marker for the bright structures, whereas the difference $\operatorname{gdir}_{\lambda}^{\phi}(f)-g \operatorname{dir}_{\lambda}^{\gamma}(f)$ marks the location of the dark structures. The watershed transform (WS) is applied and the extracted watershed lines (Beucher and Meyer, 1992) are multiplied by the computed field strength differences. For the bright structures, the watershed is computed in the $f$ image, whereas the complementary image is used for the dark structures. This operation generates thin lines that incorporate the strength of the directional fields.

Fig. 3B shows the final marker matrices. A hysteresis threshold (double threshold, $D B L T$ ) is applied producing two binary marker images ( $m_{\text {dark }}$ and $m_{\text {bright }}$; Fig. $3 \mathrm{C}$ ). The described segmentation procedure is

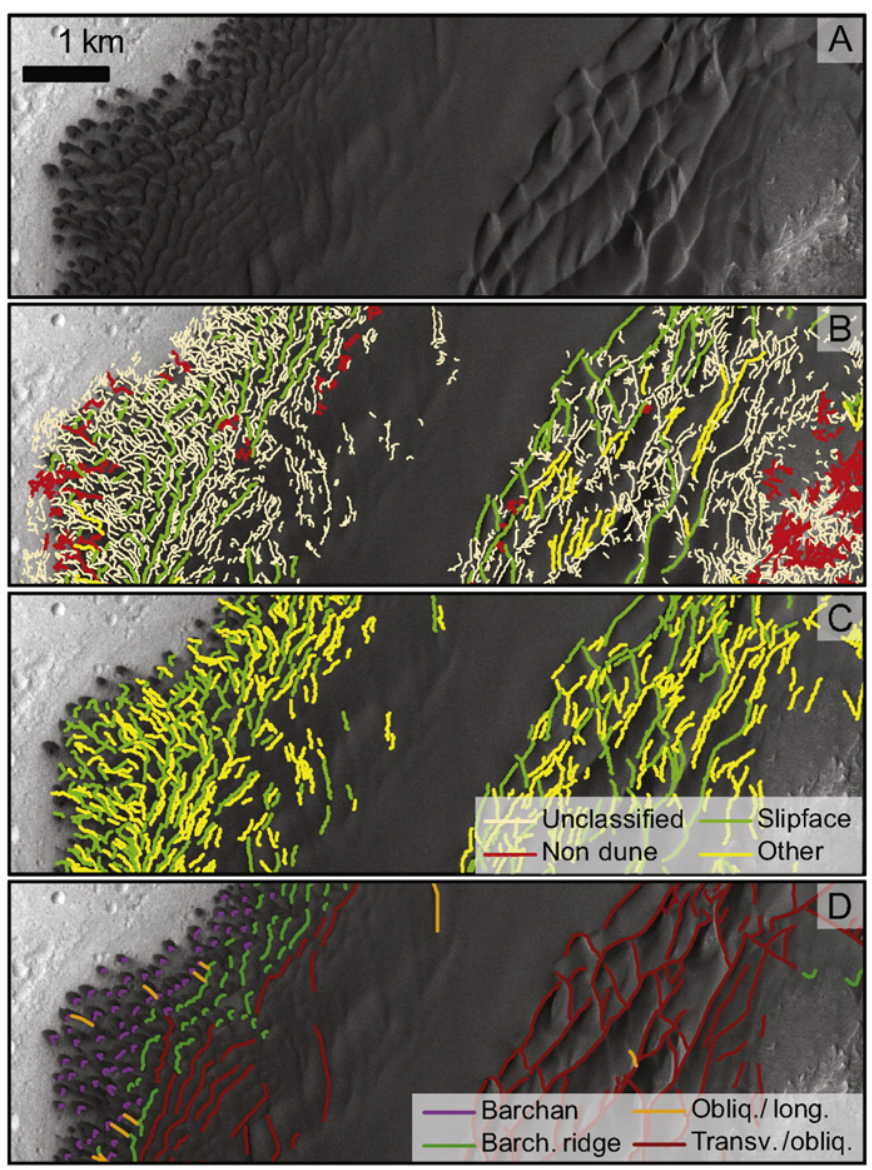

Fig. 5. Gale crater classification example (see Fig. 1D for location). (A) CTX mosaic; (B) training data set with the color code representing the three classes used for objectbased classification; (C) output classified objects, those classified as non-aeolian were removed and the features that correspond to slipfaces are shown; (D) dune morphologies mapped by photointerpretation, where the displayed classes correspond to the interpreted dune types. See Table 1 for a quantitative overview of the classification stage.

summarized in Eq. (1):

$m_{\text {bright }}=D B L T_{\left[t_{1}<t_{2}<t_{m a}\right]}\left\{W S(f) \times\left[\operatorname{gdir}_{\lambda}^{\phi}(f)-g \operatorname{dir}_{\lambda}^{\gamma}(f)\right]\right\}$
$m_{\text {dark }}=D B L T_{\left[t_{1}<t_{2}<t_{\text {ma }}\right]}\left\{W S\left(f^{c}\right) \times\left[\operatorname{gdir}_{\lambda}^{\gamma}(f)-g \operatorname{dir}_{\lambda}^{\phi}(f)\right]\right\}$

where

$f=g *\left[\begin{array}{lll}1 / 9 & 1 / 9 & 1 / 9 \\ 1 / 9 & 1 / 9 & 1 / 9 \\ 1 / 9 & 1 / 9 & 1 / 9\end{array}\right]$

The same vectorization procedure described in Vaz (2011) is followed. It includes: (i) skeletonization and pruning of small line segments; (ii) vectorization using Freeman chain coding; and (iii) object splitting using wavelet multiscale shape analysis followed by sequential merging using trend and distance thresholds (for details see Vaz, 2011).

Finally, a database containing several object descriptors is created. For each object, several types of parameters are computed: (i) geodesic measurements (trend, length, sinuosity); (ii) summary spectral parameters (note that because blending, normalization, and bandpass fusion algorithms were used to produce the mosaics, the computed parameters are not absolute reflectance values); (iii) image summary textural parameters (local entropy, morphological directional field azimuths and strengths, width of the binary objects); (iv) THEMIS IR thermophysical data (Edwards et al., 2011); and (v) morphometric parameters (slope, aspect angle, profile curvature, elevation, and longitudinal attitude of the objects). Minimum, maximum, 
mean, and standard deviation are the statistics computed for all scalar parameters; while mean vector azimuth, magnitude, and circular standard deviation are computed for angular/directional parameters.

Figs. 3D and 4 show some of these parameters in map view. One of the most important advantages of this method is that it enables the integration of different data sources, with different characteristics and spatial resolutions in objects whose geomorphological meaning will be better discussed in Section 4. First, it must be noted that a large number of mapped objects do not correspond to dune morphologies. Many bedrock features and small secondary objects are present, complicating subsequent analysis of the dune morphologies. To solve this issue, a supervised classification method is applied in order to segment the objects that actually correspond to dune morphologies.

\subsection{Object classification}

The compiled object descriptors are used as input to a supervised classification using artificial neural network (ANNs) classifiers. To avoid any potential directional bias caused by the normal clustering of dune trends in a given area, we decided not to use any of the directional parameters mentioned in the previous section (azimuth, longitudinal dip direction, mean aspect angle, and directional fields). This makes the classification process independent of the trend of the mapped objects, making it more robust for application in other areas where preferential trends may be different.

The input feature space is obtained by scaling all the input descriptors to the $[-1,1]$ interval. A feedforward ANN architecture with one input layer (42 nodes), two hidden ( 30 and 15 nodes), and one output layer ( 2 nodes) is used. Hyperbolic tangent functions are used as transfer functions, and the conjugate gradient backpropagation algorithm (Moller, 1993) is used for training.

Training data sets were created for the two areas by manual classification of $15 \%$ of the recognized objects (Fig. 5). Classification is performed in two steps: (i) non-dune and dune-related morphologies are initially segmented; and (ii) the objects previously classified as dune morphologies are again segmented in order to identify those that correspond to slipface traces. Overall, this corresponds to a classification with three output classes. However, by dividing the procedure into two sequential classification steps, higher classification accuracies are obtained. The intent is to exclude all the non-dune morphologies from any subsequent data classification/analysis.

The ANNs trained in one area were applied in that same area, but a combined training data set (including the training data sets of both areas) was also used to evaluate the robustness and scalability of the procedure. Having a classifier that can be used on a different area, for which training data sets may not be available, is key to extending this mapping approach to a regional or even global scale.

\subsection{Generalization of dune pattern descriptive parameters}

As will be shown in the following sections, the mapped objects can provide a valid discretization of the dune morphologies. Here we show how they can be used for pattern analysis, laying the foundations for future work and allowing the evaluation of errors associated with the OBDA technique.

In this analysis, we only include objects that were classified as dune morphologies using the ANN classifiers trained on the same area of analysis. Global average dune trends of large areas can probably be useful to define large-scale circulation patterns, but they obviously fail to
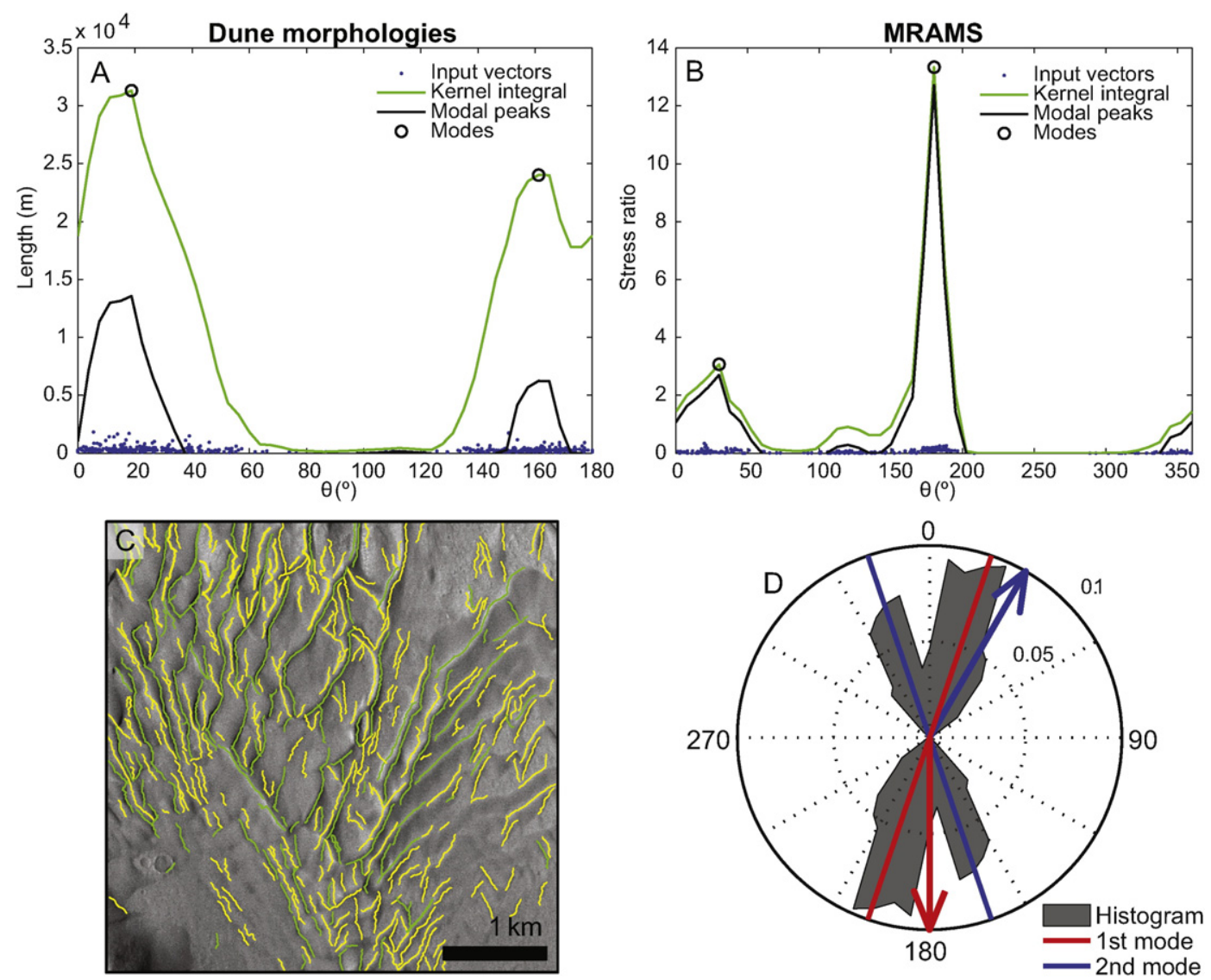

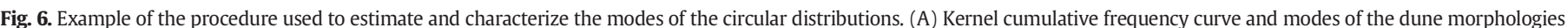

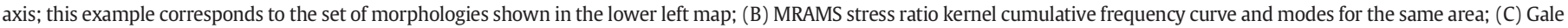

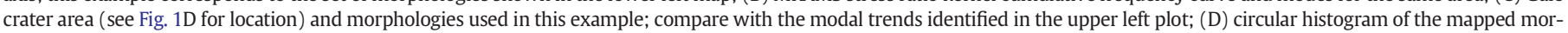
phologies (each object was weighted using its length) overlain by the automatically derived primary and secondary axes (for the morphologies) and vectors (for the MRAMS output). 


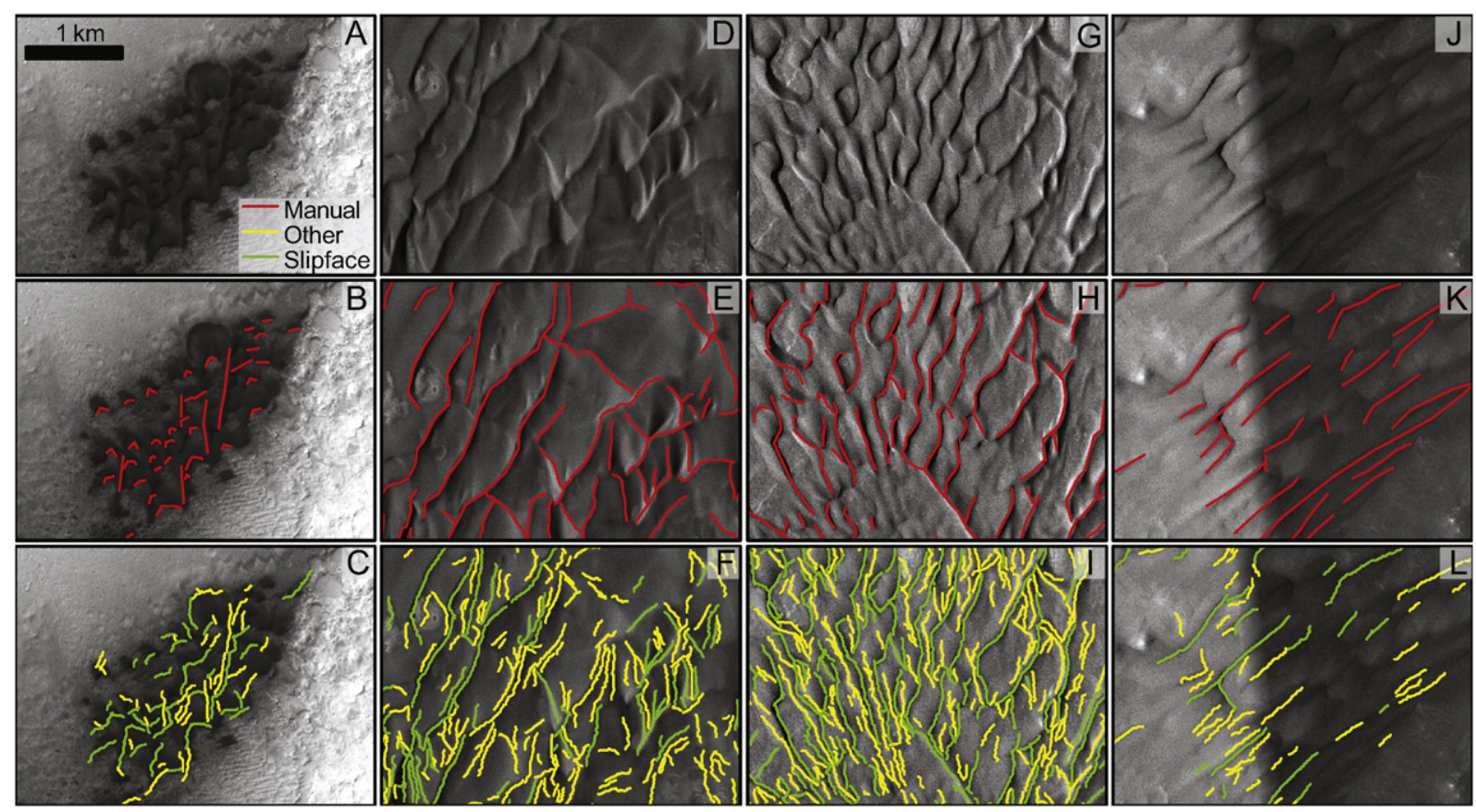

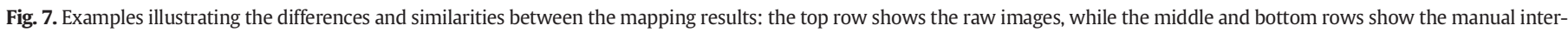



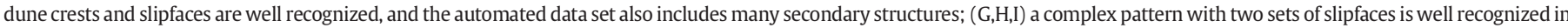

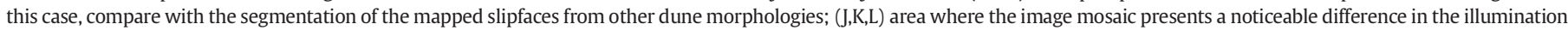
conditions, this long-wavelength mosaic defect does not influence the mapping results.
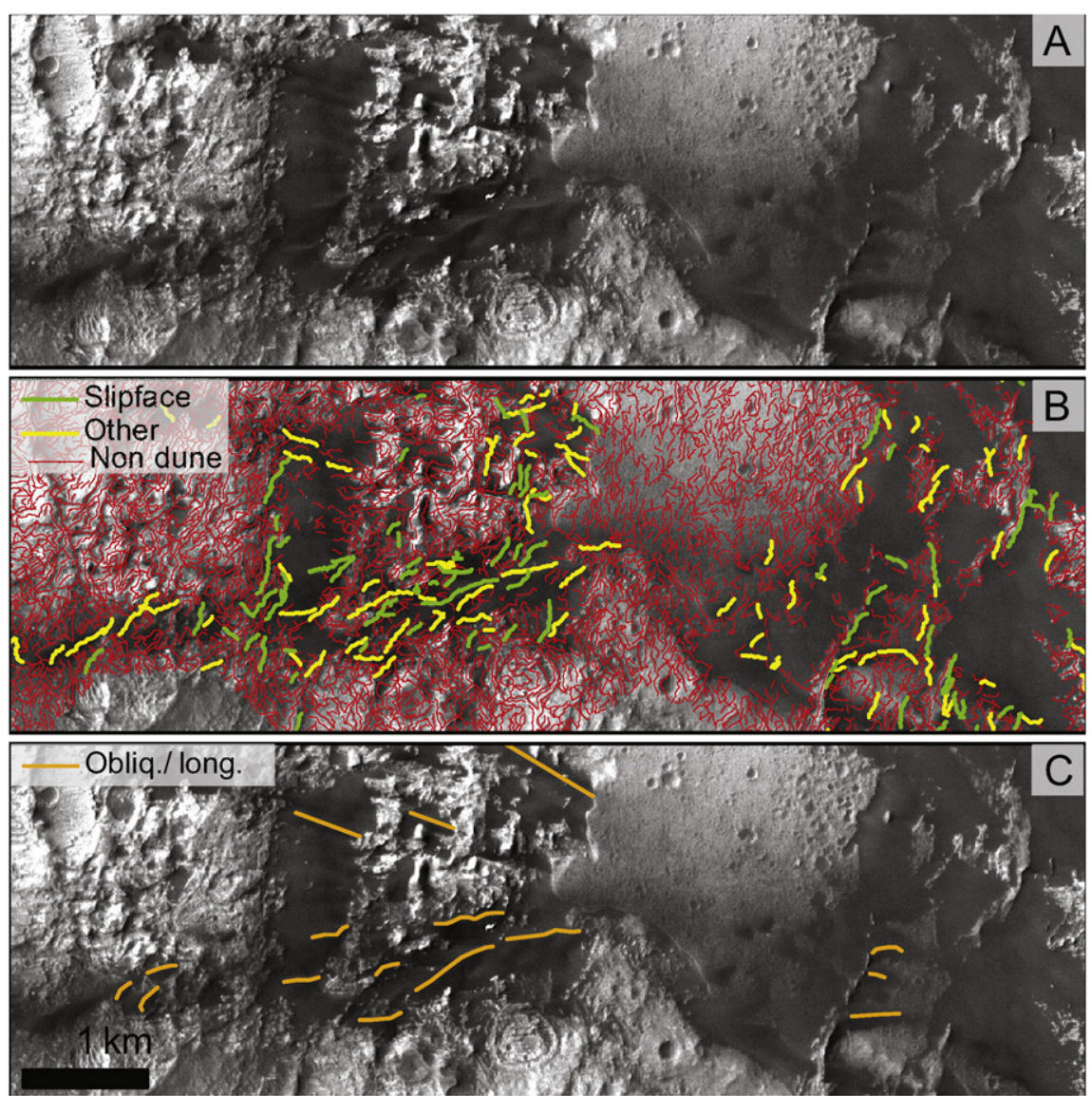

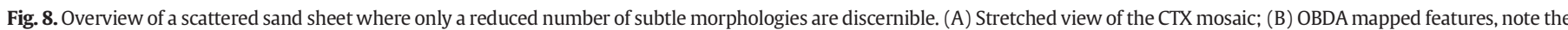
high number of bedrock linear features correctly segmented; (C) features obtained by photointerpretation, compare with (B). 
Table 1

Overall accuracies $(o a)$ and $\mathrm{k}$ index $(k)$ computed from the confusion matrices for the two classification steps ${ }^{\mathrm{a}}$

\begin{tabular}{llrrr}
\hline & \multicolumn{2}{c}{ Gale } & \multicolumn{1}{c}{ Ganges } & \multicolumn{1}{c}{ Total } \\
\hline Step 1 & oa & 95.23 & 92.73 & 94.92 \\
& $k$ & 0.77 & 0.76 & 0.76 \\
Step 2 & oa & 85.32 & 89.62 & 85.32 \\
& $k$ & 0.71 & 0.77 & 0.71 \\
Step 1 $1+2$ & oa & 93.85 & 91.13 & 93.52 \\
& $k$ & 0.71 & 0.73 & 0.70 \\
& $N$ & 216,303 & 24,942 & 241,245 \\
& $N_{t}$ & 29,192 & 5818 & 35,010
\end{tabular}

a The results of the supervised classification are shown for each area (Gale crater and Ganges Chasma), while the results of using a combined training data set are shown in the last column. $N$ and $N_{t}$ are the total number of classified objects and the number of objects in the training/validation data set.

address the diversity of dune types and the complex relations between the trends of dune morphologies and the prevailing directions of winds and sediment transport. It is beyond the scope of this paper to discuss those relations in depth, but the future use of the OBDA output for this purpose is dependent on the correct identification of the main trends at a local scale and in complex dune settings. To evaluate if this will be feasible in the future, we have created a sampling grid (with a distance between nodes of $2 \mathrm{~km}$, the same resolution of the MRAMS output computed for Gale crater) for which objects' zonal circular statistics were collected (using a sampling radius of $1.5 \mathrm{~km}$ ). Besides computing the mean axis trend, magnitude, and angular dispersion, we have implemented a kernel analysis of the circular distributions that is described in the following section.

We will only discuss the directional analysis of the dune morphologies, but other object descriptors (morphometric, spectral, textural, etc.) can also be added to this grid, providing a unique sparse representation of the dune patterns. The described procedure can be seen as the creation of another level of objects, ideal for the integration and crossanalysis of dune pattern parameters and mesoscale wind models.

\subsubsection{Estimating and characterizing circular modes}

When analyzing the circular distribution of directional or axial data, mean vector azimuth and magnitude, circular variance, and standard deviations are the preferred statistical parameters used for exploratory data analysis (Mardia and Jupp, 2000). However, these parameters do not provide any insight into the modality of the circular distribution. This is commonly accomplished by visual analysis of rose diagrams,
Table 2

Summary statistics for the two mapped data sets (the manual data set corresponds to the photointerpretations, while the OBDA data set corresponds to the data sets obtained after the removal of non-dune morphologies) ${ }^{\mathrm{a}}$.

\begin{tabular}{llrlllr}
\hline Area & Data set & $\sigma\left(^{\circ}\right)$ & $L(\mathrm{~m})$ & $V$ & $v\left(^{\circ}\right)$ & \multicolumn{1}{l}{$N$} \\
\hline Ganges Chasma & Manual & 11.9 & 227.6 & 0.41 & 59.2 & 1196 \\
& OBDA & 6.7 & 161.1 & 0.50 & 67.3 & 3161 \\
Gale crater & Manual & 12.8 & 157.9 & 0.67 & 84.7 & 2725 \\
& OBDA & 8.2 & 117.8 & 0.57 & 74.4 & 12,058 \\
\hline
\end{tabular}

a The mean vector azimuth $(\sigma)$, mean length $(L)$, circular variance $(V)$, circular standard deviation $(v)$, and the total number of mapped lineaments $(N)$ are the presented parameters. See text for discussion and Fig. 9 for the corresponding length-weighted circular distributions.

which in our case would render impossible a concise analysis of the results.

In fact, a preliminary analysis of the OBDA outputs revealed that mapped dune morphologies are rarely unimodal at a local scale (see the example in Fig. 6C). In addition we also needed to analyze and compare axial data (the trends of the mapped morphologies) and directional data (the MRAMS modeled winds, normalized by the saltation threshold). To achieve all these purposes we have: (i) generated cumulative distributions by computing a kernel sum of the input vectors (Fig. 6A and B); (ii) segmented the distribution peaks by applying a top-hat morphological operator (Soille, 2002); (iii) computed for each segmented distribution peak the maximum location and kernel frequency; and (iv) computed a kernel frequency ratio between the secondary and primary modes quantifying the bimodality of the circular distribution (when only one peak is segmented the value of this ratio is zero, indicating a unimodal distribution).

Because data are circular, the wrapping of the distribution is considered when computing the cumulative kernel densities. For axial data all computations are done after doubling the angles, and in the end the obtained modal trends are halved. This is the same procedure usually applied for the statistical analysis of axial data (Mardia and Jupp, 2000). The angular kernel bandwidth used in all examples was $30^{\circ}$. The same value is used to define the size of the linear structuring element used to segment the modal maxima. Fig. 6 illustrates the described procedure. The input axis/vectors trends and magnitudes (length of the mapped morphologies or MRAMS stress ratio) are used to compute a kernel cumulative curve. This curve is then used to segment the modal peaks, from which the location/trend of the modes is computed.

The trends, kernel modal frequencies, and the modal ratio that gives the degree of bimodality for a certain distribution are computed locally
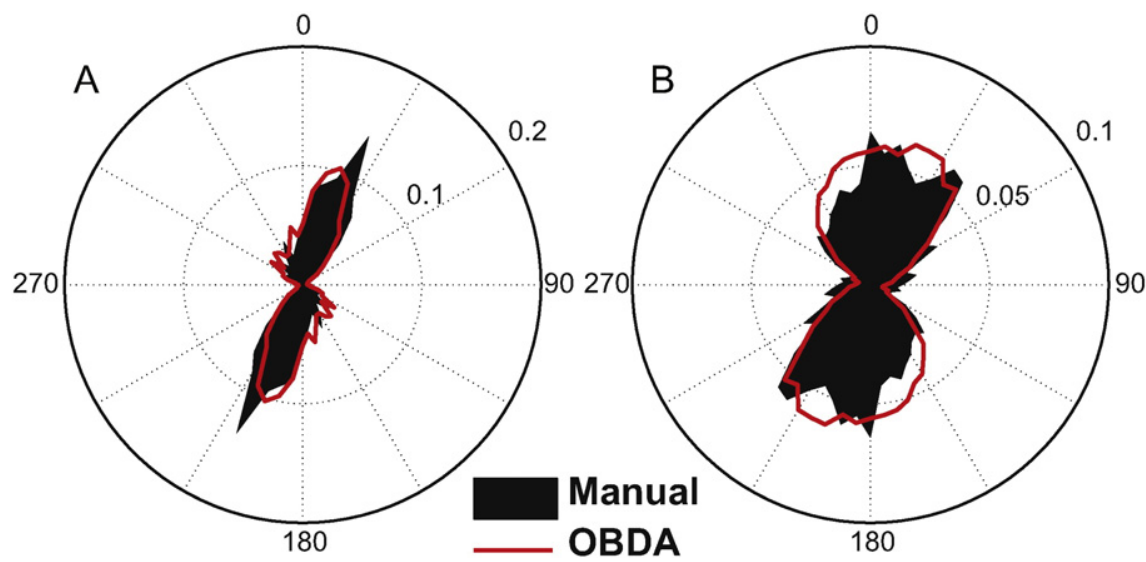

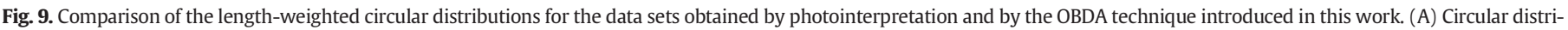

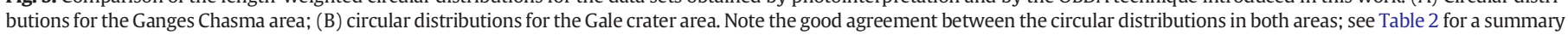
of the circular statistics. 

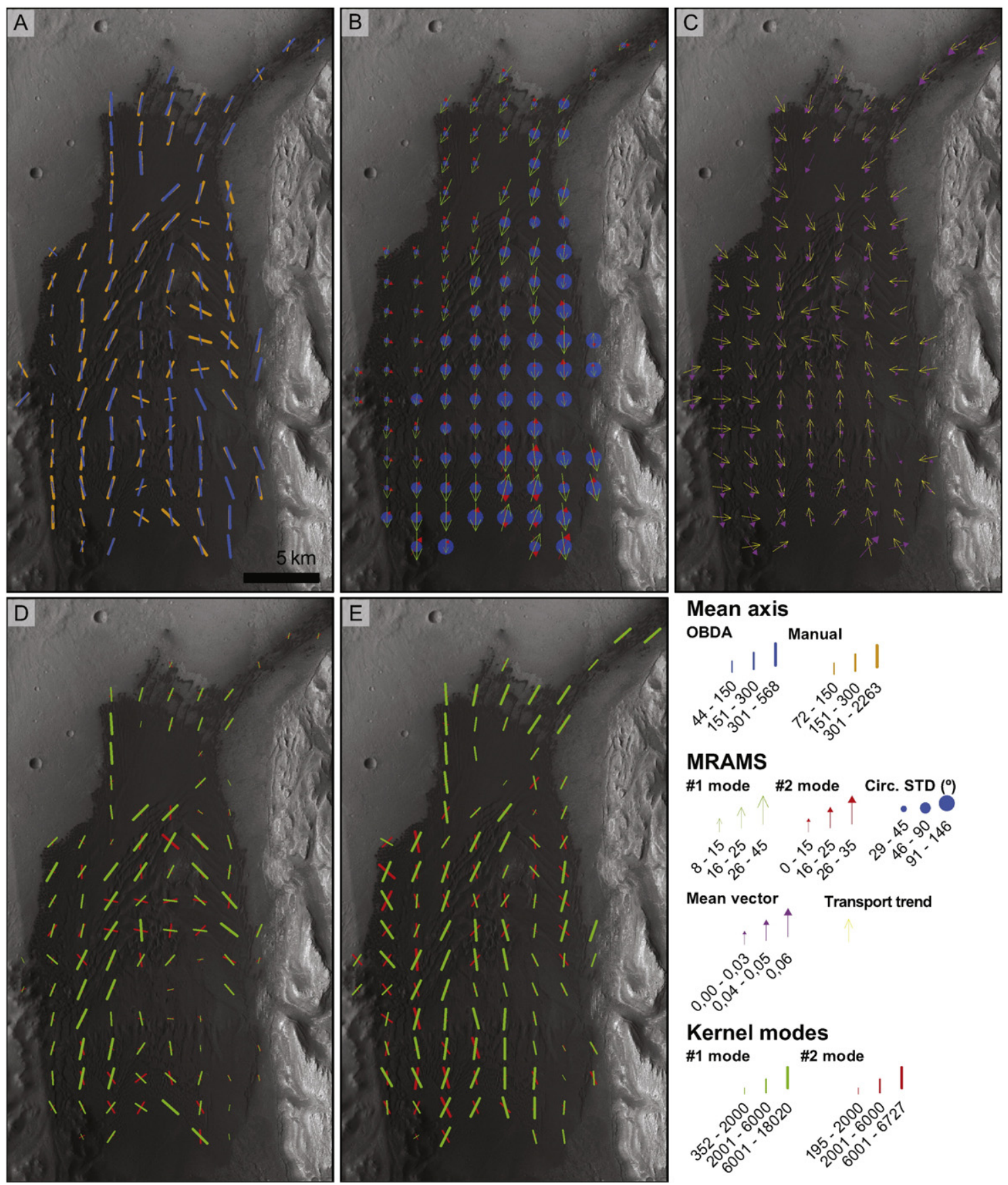

\section{Mean axis}

OBDA

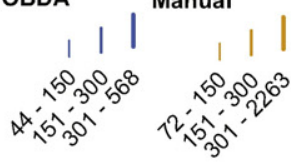

MRAMS

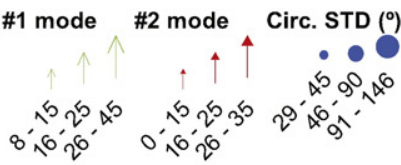

Mean vector Transport trend

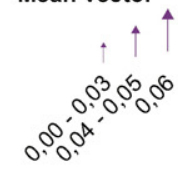

\section{Kernel modes}

\#1 mode \#2 mode

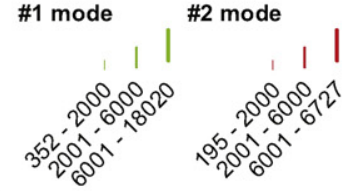

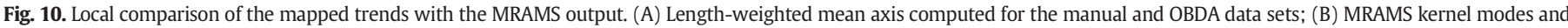

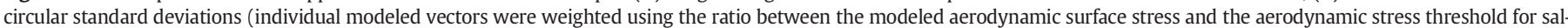

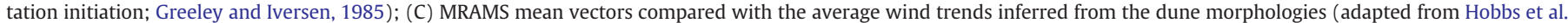

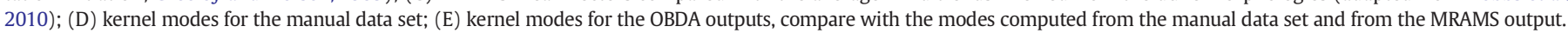

for each grid node. In order to assess the local accuracy of the OBDA approach, we have integrated in the same sampling grid the MRAMS output as well as the same directional parameters computed from the manually mapped data sets.

\section{Results and validation}

The mapping results are compared with the photointerpretations of the two analyzed areas. To validate and estimate the accuracy of the technique, a quantitative assessment mainly focused on the comparison of the circular statistics of the mapped features is presented. A qualitative comparison of the results highlights the differences between the manually mapped morphologies and those mapped automatically by the OBDA approach.

\subsection{Qualitative comparison}

In Figs. 5 and 7 clearly many of the identified objects/structures do not correspond to slipfaces, nonetheless in many cases they correspond to other linear dune morphologies such as dune crests, limbs, horns, ridges, etc. This is the main reason for implementing the supervised segmentation of slipfaces. These are the geomorphologic features preferentially mapped and analyzed because they can be directly linked to bulk sediment transport and winds. Even so, the proposed method allows for 
recognition of other structures that can contribute to a more complete characterization of dune fields.

The comparative examples shown in Fig. 7 highlight the output obtained for different dune types and trends. Small barchan dunes (Fig. 7A, B, C) are the type of dunes where the OBDA mapped structures differ most from the manually mapped data set. In this case, slipfaces are not always correctly mapped. The spatial resolution of the mosaic is commonly not sufficient to allow the definition of objects representing barchan slipfaces, which in map view can correspond to areas of only 7 by 2 pixels. In this case, barchan horns and limbs are preferentially mapped, as they represent linear features with a larger map expression.

Other dune types such as barchanoid ridges (Fig. 5B), reversing, and star dunes (Fig. 7F), are better represented because they are composed of larger-scale linear features. Besides the slipfaces, other secondary morphologic structures are also recognized. In cases where dune morphologies are multimodal (Fig. 7I), all modal trends are also correctly recognized.

Mosaic defects, such as uneven illumination conditions, do not greatly influence the results (Fig. 7F). Even so, smooth linear structures that probably correspond to large wavelength undulations on the sand beds are not completely recognized. Note that in this case, the relationship between illumination settings and the trend of the structures can enhance or conceal them. This directional bias is not easily quantifiable, however, and may also affect photointerpretations (Smith and Wise, 2007).

In areas where large-scale dune morphologies are absent, or are not recognizable at the resolution of the imagery used, the OBDA output is still roughly consistent with photointerpretations. See for instance Fig. 8, which shows an example of a patchy sand sheet with elongated structures. Although large ridges or slipfaces are not evident, the main trends of the aeolian deposits are still correctly identified - namely the set of EW to NW-SE longitudinal morphologies. A secondary set trending NNE-SSW is present in the eastern region where it marks the accumulation of sediments in the leeward of topographic obstacles. Many of these dark-shadowed areas were misclassified as slipfaces. Even so, the vast majority of bedrock features were correctly assigned to the non-dune class, while the identified dune morphologies still portray the main axis of sediment transport and accumulation.

There are also considerable differences in the style of mapping between the two techniques. Sinuous and continuous long lines are generally the result of photointerpretation (Fig. 7E), while OBDA objects usually present a larger degree of segmentation. Depending on the type of dunes under analysis, photointerpretation is more focused in the mapping of one specific type of morphology; see for instance Fig. 7H where only crestlines were mapped. The OBDA results in this case are far more complete, with the correct identification of slipfaces and other morphologies. Despite these differences, the OBDA results are able to correctly identify the main geomorphologic trends. A quantitative assessment of the degree of directional agreement is presented in the following section.

\subsection{Quantitative assessment}

To start with, we will evaluate the performance of the classification procedure. This processing step enables the elimination of objects that do not correspond to dune morphologies and the segmentation of slipfaces. The overall accuracy (oa) and $k$ index $(k)$ are the parameters computed from the confusion matrices (Tso and Mather, 2001) to evaluate the classification results. The overall accuracy ranges from 0 to $100 \%$, with $100 \%$ denoting perfect agreement; while $k$ ranges from 0 to 1 , with 1 denoting perfect agreement and 0 a random non-agreement case.

For the first classification stage, we obtained overall accuracies between 93 and $95 \%$ and a $k$ of 0.76 (Table 1). These numbers prove that the segmentation of dune-related morphologies is highly accurate. The success rate of the second stage of classification is lower (85-90\% and $0.71-0.77$ ), but the values of $k$ still indicate a substantial degree of agreement (Landis and Koch, 1977) between the validation and output classified data sets. When all stages are analyzed together (considering three classes), similar values are obtained (91-94\% and 0.7). The classification process seems to be equally robust for the dune fields within Gale crater and Ganges Chasma, and the performance is not seriously affected by the use of training data sets from other areas. In summary, the classification stage enables the removal of the large majority of objects that do not correspond to dune morphologies and the efficient segmentation of those that correspond to slipfaces.

The global length-weighted circular distributions for each area and for the two compared data sets are shown in Fig. 9; the agreement between the global trends of the mapped structures is apparent. Table 2 summarizes the circular statistics for each population, and it shows that for all cases the maximum angular difference between the computed mean axis is $5^{\circ}$. The circular standard deviations differ as much as $10^{\circ}$, but the OBDA estimates also point to a higher dispersion of trends in the Gale crater dune field. The major difference is that OBDA generates a larger number of smaller lines, as previously discussed.

An example of the local grid used to generalize the pattern trends is shown in Fig. 10. The example covers the dune field located in the western region of Gale and displays several directional parameters. MRAMS output (Fig. 10B and C) shows primary winds blowing from the NNE, which are particularly relevant in the northern section of the dune field. In the east and southeast a significant secondary S-SSW trend is
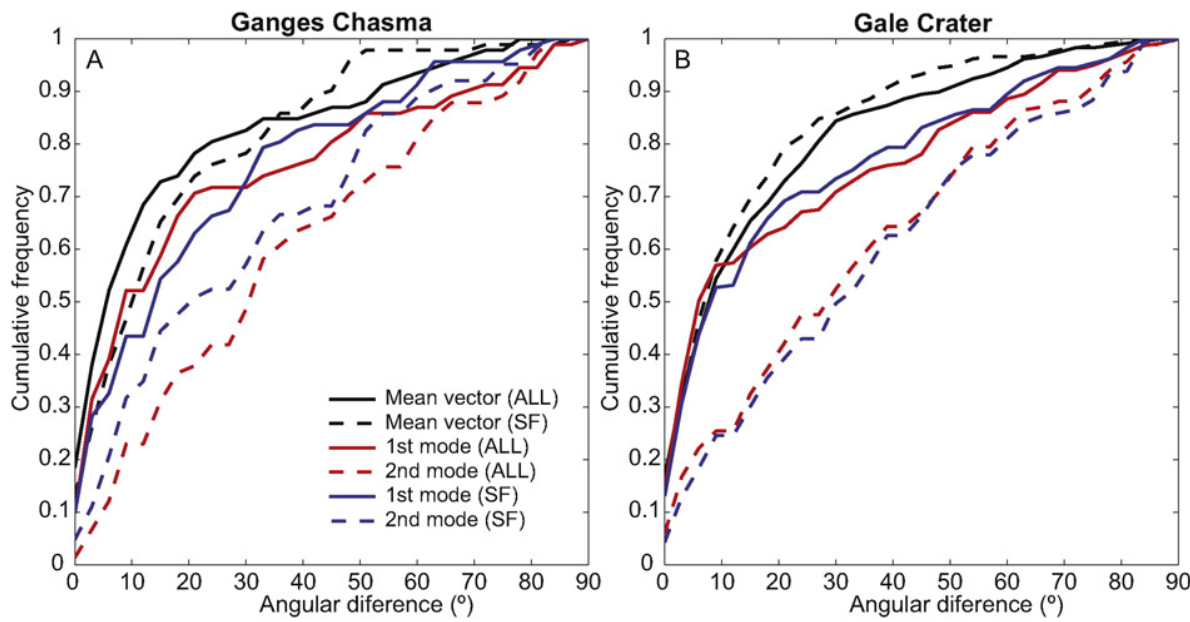

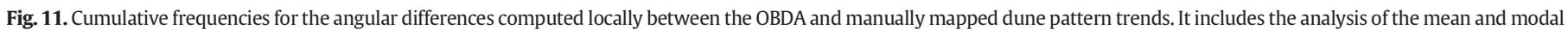
axis trends for all the OBDA-mapped dune morphologies (ALL) and for the subset of those classified as slipfaces (SF). 
present, while in the western central section secondary winds blowing from WNW are in agreement with the inferred sediment transport trends (Fig. 10C) derived from the barchan dunes shown in Fig. 5D. The predicted dispersion of the winds is larger on the SE quadrant of the dune field, but modeled winds are never unimodal (Fig. 10B). This implies that the mean vectors computed from the MRAMS outputs do not match the transport trends inferred from the morphologies. Instead, in most of the cases these trends best match one of the computed kernel modes.

When visually compared, the mean vectors of the two compared data sets (OBDA and manually mapped data sets, Fig. 10A) present considerable trend differences in certain areas. But a better perspective is obtained when the trends of the kernel modes are compared (Fig. 10D and $\mathrm{E}$ ); and it becomes more evident that a much better match exists for the primary mode trends, while secondary modes differ greatly in trend and relative kernel strength. This fact is probably related to the mapping of a large number of secondary features by the automated technique (see the examples given in Fig. 7). Nevertheless, the good agreement between the MRAMS primary modal trends and the primary modal axis of the OBDA output is evident, suggesting that the majority of the mapped dune morphologies in this example are longitudinal or oblique in nature.

The trends of the mean axis, primary and secondary modes of the two compared data sets were used to compute the cumulative histograms of the angular differences (the acute angle between the two axes) (Fig. 11). This analysis was performed for the totality of the mapped dune-related morphologies (the 'ALL' set) and for a subset corresponding to the features classified as slipfaces ('SF'). Only grid nodes that aggregate information of more than two objects are used in this assessment.

From this comparative analysis we conclude that $~ 75 \%$ of OBDA mean vectors deviate $<20^{\circ}$ from the average vectors computed from the photointerpreted data set. By only considering the 'SF' subset, this percentage rises to $80 \%$ for Gale crater. This demonstrates the importance and usefulness of the slipface trace segmentation, especially in the analysis of large areas with considerable diversity of dune types. The deviations in the primary modes are generally higher, with 65$70 \%$ of the cases with deviations $<20^{\circ}$, while for secondary modes this percentage decreases to $35-45 \%$. As discussed earlier, this can be related to the large number of small secondary features correctly mapped by the OBDA approach, which are usually not as well represented in photointerpretation.

Taking into account that a maximum $45^{\circ}$ variation may be acceptable for regional studies (as it is still indicative of the directional quadrant), we conclude that the identified secondary modes are within acceptable ranges on $65 \%$ of the mapped area, while mean and primary modal axis were correctly recognized in $80-95 \%$ of the total area. These are values that attest to the high level of agreement between the mapped trends.

\section{Discussion and future perspectives}

So far we have validated and provided accuracy estimates for the introduced automated dune mapping procedure. In order to test the robustness of the method, we used two areas with heterogeneous dune types and complex dune spatial arrangements. As seen in the previous section, the method performs better for dune types that in map view are composed of long linear segments. When compared with photointerpretations, slipfaces of smaller barchans are less well represented, with the preferential mapping of the lateral flanks that in map view present a larger linear signature.

In this work our major concern was to present the technique and compare the results with the human-made photointerpretations. The ability to quickly map and characterize dune patterns over large areas using an objective, consistent, and reproducible technique is by itself a major improvement. Furthermore, the mapped objects can naturally integrate dune pattern characteristics, spectral and morphometric parameters as well as output from atmospheric models. The analysis of such a data set will certainly require the use of multivariate statistical methods, such as principal component analysis, clustering, or multivariate correlations. Such techniques may be used to investigate the causes of spatial variations of dune patterns on Mars or elsewhere. The interplay between winds and dune patterns, automated dune type recognition, or the mapping of sediment transport paths over vast areas are some of the tasks that can be addressed in the future using the presented method.

\section{Conclusion}

The described technique provides an automated method of detection and facilitates the measurement of relevant parameters that can be used to characterize dunes on Mars. A meaningful and reproducible analysis can now be performed for vast areas, using image mosaics and with minimum human intervention. Despite that, verification and editing of the obtained results by an experienced researcher can be necessary to improve the results, particularly in areas where small barchans dunes are present.

Object-based classification accuracies of 95\% were attained for the segmentation of objects that represent dune morphologies. From this set, we were able to segment objects that correspond to slipface traces with an accuracy of 85-90\%. Global circular distributions of the mapped features are consistent with photointerpretations, with average axis trend variations within $5^{\circ}$. From the local comparison of the directional parameters, we conclude that the mapping results are strongly correlated with the photointerpretations. This validation shows that average and primary modal trends are within acceptable limits for $80-95 \%$ of the total mapped area.

Rather than trying to analyze and explain any dune morphology, this study is only focused on their correct mapping and characterization using an automated, objective and reproducible methodology. By generating and condensing an array of data that can be used to characterize dune fields at regional or even global scale on Mars, this method will surely contribute to the enrichment of global dune catalogs of the planet. Vegetation and human made structures will probably complicate the straightforward application of the same technique on the Earth. However, because a global dune database for our planet does not exist, the adaptation and application of the presented method would certainly increase our knowledge of Earth's dune fields.

\section{Acknowledgments}

We would like to thank the comments and suggestions made by two anonymous reviewers, as well as the diligent revision made by the editor Richard Marston. This work was supported by FCT (Fundação para a Ciência e a Tecnologia) with the grant FRH/BPD/72371/2010 and the contracts PEst-OE/CTE/UI0611/2012-CGUC and PTDC/CTE-SPA/ $117786 / 2010$.

\section{References}

Bandeira, L., Marques, J.S., Saraiva, J., Pina, P., 2011. Automated detection of Martian dune fields. IEEE Geosci. Remote Sens. Lett. 8 (4), 626-630.

Beucher, S., Meyer, B., 1992. The morphological approach to segmentation: the watershed transformation. In: Dougherty, E.R. (Ed.), Mathematical Morphology in Image Processing. Marcel Dekker, Inc., New York, pp. 433-481.

Beveridge, C., Kocurek, G., Ewing, R.C., Lancaster, N., Morthekai, P., Singhvi, A.K., Mahan, S.A., 2006. Development of spatially diverse and complex dune-field patterns: Gran Desierto Dune Field, Sonora, Mexico. Sedimentology 53 (6), 1391-1409.

Blaschke, T., 2010. Object based image analysis for remote sensing. ISPRS J. Photogramm. Remote Sens. 65 (1), 2-16.

du Pont, S.C., Narteau, C., Gao, X., 2014. Two modes for dune orientation. Geology 42 (9), 743-746.

Edwards, C.S., Nowicki, K.J., Christensen, P.R., Hill, J., Gorelick, N., Murray, K., 2011 Mosaicking of global planetary image datasets: 1 . Techniques and data processing for Thermal Emission Imaging System (THEMIS) multi-spectral data. J. Geophys. Res. Planets 116 
Elbelrhiti, H., Andreotti, B., Claudin, P., 2008. Barchan dune corridors: field characterization and investigation of control parameters. J. Geophys. Res. Planets 113 (F2).

Ewing, R.C., Kocurek, G., Lake, L.W., 2006. Pattern analysis of dune-field parameters. Earth Surf. Process. Landf. 31 (9), 1176-1191.

Fenton, L.K., Toigo, A.D., Richardson, M.I., 2005. Aeolian processes in Proctor Crater on Mars: mesoscale modeling of dune-forming winds. J. Geophys. Res. 110 (E6), E06005

Fenton, L.K., Michaels, T.I., Beyer, R.A., 2014a. Inverse maximum gross bedform-norma transport 1: how to determine a dune-constructing wind regime using only imagery. Icarus 230, 5-14.

Fenton, L.K., Michaels, T.I., Chojnacki, M., Beyer, R.A., 2014b. Inverse maximum gross bedform-normal transport 2: application to a dune field in Ganges Chasma, Mars and comparison with HiRISE repeat imagery and MRAMS. Icarus 230, 47-63.

Fernandez-Cascales, L., Lucas, A., Rodriguez, S., Narteau, C., Allemand, P., Spiga, A. Courrech du Pont, S., Garcia, A., 2015. Two modes for dune orientation on Mars. 4th International Planetary Dunes Workshop, Boise, ID (pp. \#8041).

Gardin, E., Allemand, P., Quantin, C., Silvestro, S., Delacourt, C., 2012. Dune fields on Mars: recorders of a climate change? Planet. Space Sci. 60 (1), 314-321.

Greeley, R., Iversen, J.D., 1985. Wind as a Geological Process on Earth, Mars, Venus and Titan. Cambridge University Press, New York.

Greeley, R., Thompson, S.D., 2003. Mars: Aeolian features and wind predictions at the Terra Meridiani and Isidis Planitia potential Mars Exploration Rover landing sites. J. Geophys. Res. Planets 108 (E12).

Hay, G.J., Castilla, G., 2008. Geographic Object-Based Image Analysis (GEOBIA): a new name for a new discipline. In: Blaschke, S.L.T., Hay, G.J. (Eds.), Object-Based Image Analysis. Spatial Concepts for Knowledge-driven Remote Sensing Applications. Springer-Verlag, pp. 75-89.

Hayward, R.K., Mullins, K.F., Fenton, L.K., Hare, T.M., Titus, T.N., Bourke, M.C., Colaprete, A. Christensen, P.R., 2007. Mars Global Digital Dune Database and initial science results. J. Geophys. Res. Planets 112 (E11), E11007.

Hayward, R.K., Titus, T.N., Michaels, T.I., Fenton, L.K., Colaprete, A., Christensen, P.R., 2009 Aeolian dunes as ground truth for atmospheric modeling on mars. J. Geophys. Res. Planets 114.

Hayward, R.K., Fenton, L.K., Titus, T.N., 2014. Mars Global Digital Dune Database $(\operatorname{MGD}(3))$ : global dune distribution and wind pattern observations. Icarus 230, $38-46$.

Hobbs, S.W., Paull, D.J., Bourke, M.C., 2010. Aeolian processes and dune morphology in Gale Crater. Icarus 210 (1), 102-115.

Hugenholtz, C.H., Levin, N., Barchyn, T.E., Baddock, M.C., 2012. Remote sensing and spatia analysis of aeolian sand dunes: a review and outlook. Earth-Sci. Rev. 111 (3-4), 319-334.

Kocurek, G., Ewing, R.C., 2005. Aeolian dune field self-organization - implications for the formation of simple versus complex dune-field patterns. Geomorphology 72 (1-4), 94-105.

Landis, J.R., Koch, G.G., 1977. The measurement of observer agreement for categorical data. Biometrics 33 (1), 159-174

Lucas, A., Rodriguez, S., Narteau, C., Charnay, B., du Pont, S.C., Tokano, T., Garcia, A., Thiriet M. Hayes, A.G. Lorenz, R.D. Aharonson, O 2014. Growth mechanisms and dune orientation on Titan. Geophys. Res. Lett. 41 (17), 6093-6100.

Malin, M.C., Bell Iii, J.F., Cantor, B.A., Caplinger, M.A., Calvin, W.M., Clancy, R.T., Edgett, K.S. Edwards, L., Haberle, R.M., James, P.B., Lee, S.W., Ravine, M.A., Thomas, P.C., Wolff, M.J., 2007. Context Camera Investigation on board the Mars Reconnaissance Orbiter. J. Geophys. Res. 112 (5), E05S04.

Mardia, K.V., Jupp, P.E., 2000. Directional statistics. Wiley Series in Probability and Statistics. John Wiley \& Sons, Chichester.

Michaels, T.I., Rafkin, S.C.R., 2008. Meteorological predictions for candidate 2007 Phoenix Mars Lander sites using the Mars Regional Atmospheric Modeling System (MRAMS). J. Geophys. Res. Planets 113, E00a07.
Moller, M.F., 1993. A scaled conjugate-gradient algorithm for fast supervised learning. Neural Netw. 6 (4), 525-533.

Myint, S.W., Gober, P., Brazel, A., Grossman-Clarke, S., Weng, Q.H., 2011. Per-pixel vs. object-based classification of urban land cover extraction using high spatial resolution imagery. Remote Sens. Environ. 115 (5), 1145-1161.

Necsoiu, M., Leprince, S., Hooper, D.M., Dinwiddie, C.L., McGinnis, R.N., Walter, G.R., 2009. Monitoring migration rates of an active subarctic dune field using optical imagery. Remote Sens. Environ. 113 (11), 2441-2447.

Putzig, N.E., Mellon, M.T., 2007. Apparent thermal inertia and the surface heterogeneity of Mars. Icarus 191 (1), 68-94

Rafkin, S.C.R., Haberle, R.M., Michaels, T.I., 2001. The Mars Regional Atmospheric Modeling System: model description and selected simulations. Icarus 151 (2), 228-256.

Sefton-Nash, E., Teanby, N.A., Newman, C., Clancy, R.A., Richardson, M.I., 2014. Constraints on Mars' recent equatorial wind regimes from layered deposits and comparison with general circulation model results. Icarus 230, 81-95.

Silvestro, S., Di Achille, G., Ori, G.G., 2010. Dune morphology, sand transport pathways and possible source areas in east Thaumasia Region (Mars). Geomorphology 121 (1-2), 84-97.

Silvestro, S., Vaz, D.A., Fenton, L.K., Geissler, P.E., 2011. Active aeolian processes on Mars: a regional study in Arabia and Meridiani Terrae. Geophys. Res. Lett. 38 (20), L20201.

Silvestro, S., Vaz, D.A., Ewing, R.C., Rossi, A.P., Fenton, L.K., Michaels, T.I., Flahaut, J., Geissler, P.E., 2013. Pervasive aeolian activity along rover Curiosity's traverse in Gale Crater, Mars. Geology 41 (4), 483-486.

Smith, M.J., Wise, S.M., 2007. Problems of bias in mapping linear landforms from satellite imagery. Int. J. Appl. Earth Obs. Geoinf. 9 (1), 65-78.

Smith, D.E., Zuber, M.T., Frey, H.V., Garvin, J.B., Head, J.W., Muhleman, D.O., Pettengill, G.H., Phillips, R.J., Solomon, S.C., Zwally, H.J., Banerdt, W.B., Duxbury, T.C., Golombek, M.P., Lemoine, F.G., Neumann, G.A., Rowlands, D.D., Aharonson, O., Ford, P.G., Ivanov, A.B., Johnson, C.L., McGovern, P.J., Abshire, J.B., Afzal, R.S., Sun, X., 2001. Mars Orbiter Laser Altimeter: experiment summary after the first year of global mapping of Mars. J. Geophys. Res. 106 (E10), 23689-23722.

Soille, P., 2002. Morphological Image Analysis - Principles and Applications. SpringerVerlag, Berlin.

Telfer, M.W., Fyfe, R.M., Lewin, S., 2015. Automated mapping of linear dunefield morphometric parameters from remotely-sensed data. Aeolian Res. (in press).

Tso, B., Mather, P.M., 2001. Classification Methods for Remotely Sensed Data. Taylor \& Francis, New York.

Vaz, D.A., 2011. Analysis of a Thaumasia Planum rift through automatic mapping and strain characterization of normal faults. Planet. Space Sci. 59 (11-12), 1210-1221.

Vaz, D.A., Silvestro, S., 2014. Mapping and characterization of small-scale aeolian structures on Mars: an example from the MSL landing site in Gale Crater. Icarus 230, 151-161.

Vaz, D.A Di Achille, G, Barata, M.T, Alves, E.I, 2012. Tectonic lineament mapping of the Thaumasia Plateau, Mars: comparing results from photointerpretation and a semiautomatic approach. Comput. Geosci. 48(0), 162-172.

Vaz, D.A., Spagnuolo, M.G., Silvestro, S., 2014. Morphometric and geometric characterization of normal faults on Mars. Earth Planet. Sci. Lett. 401, 83-94.

Vermeesch, P., Drake, N., 2008. Remotely sensed dune celerity and sand flux measurements of the world's fastest barchans (Bodélé, Chad). Geophys. Res. Lett. 35 (24), L24404.

von Gioi, R.G., Jakubowicz, J., Morel, J.M., Randall, G., 2012. LSD: a line segment detector. Image Processing On Line 2, pp. 35-55.

Ward, A.W., Doyle, K.B., Helm, P.J., Weisman, M.K., Witbeck, N.E., 1985. Global map of eolian features on Mars. J. Geophys. Res. Solid Earth 90 (B2), 2038-2056.

Whiteside, T.G., Boggs, G.S., Maier, S.W., 2011. Comparing object-based and pixel-based classifications for mapping savannas. Int. J. Appl. Earth Obs. Geoinf. 13 (6), 884-893. 